\title{
Smart Drug Delivery Strategies for Cancer Therapy
}

\author{
Carlos Miguel López Mendoza ${ }^{1}$ and Luz Eugenia Alcántara Quintana ${ }^{2 *}$ \\ ${ }^{1}$ Unidad de Innovación en Diagnóstico Celular y Molecular, Coordinación para la Innovación y la Aplicación de la Ciencia y la \\ Tecnología, Universidad Autónoma de San Luis Potosí, San Luis Potosí, Mexico, ${ }^{2}$ Cátedra CONACYT, Unidad de Innovación en \\ Diagnóstico Celular y Molecular, Coordinación para la Innovación y la Aplicación de la Ciencia y la Tecnología, Universidad \\ Autónoma de San Luis Potosí, San Luis Potosí, Mexico
}

OPEN ACCESS

Edited by:

Zhiqing Pang,

Fudan University, China

Reviewed by:

Raj Kumar,

University of Nebraska Medical

Center, United States

Jose L. Rodríguez-López,

Instituto Potosino de Investigación

Científica y Tecnológica (IPICYT),

Mexico

${ }^{*}$ Correspondence:

Luz Eugenia Alcántara Quintana luz.alcantara@uas/p.mx lealcantara@conacyt.mx

Specialty section: This article was submitted to Biomedical Nanotechnology, a section of the journal Frontiers in Nanotechnology

Received: 05 August 2021 Accepted: 20 December 2021

Published: 20 January 2022

Citation:

López Mendoza CM and Alcántara Quintana LE (2022) Smart Drug Delivery Strategies for Cancer Therapy.

Front. Nanotechnol. 3:753766. doi: 10.3389/fnano.2021.753766
Chemotherapy is one of the most widely used strategies to fight cancer, although it has disadvantages such as accumulation in healthy organs and lack of specificity by cancer cells (non-targeted molecules), among others, resulting in adverse effects on patients that limit the dose or follow-up with the same. However, the treatment can also fail due to the resistance mechanisms that cancer cells have to these agents. Because of these limitations, smart drug delivery strategies have been developed to overcome treatment challenges. These smart drug strategies are made with the aim of passively or actively releasing the drug into the tumor environment, increasing the uptake of the chemotherapeutic agent by the cancer cells, thus reducing the adverse effects on other vital organs. Also, these strategies can be guided with molecules on their surface that interact with the tumor microenvironment or with specific receptors on the cancer cell membrane, thus conferring high affinity. This mini review summarizes advances in the development of drug delivery techniques for cancer treatment, including different smart nanocarriers with single or multifunctional stimuli responsiveness. At the same time, we highlight the toxicity and delivery of these strategies in in vivo models. Despite innovation in smart delivery techniques, there are still biodistribution and customization challenges to be overcome in future research.

Keywords: nanodevices, chemotherapy, cancer, passive delivery, active delivery, single function, multifunction

\section{INTRODUCTION}

Chemotherapy agents are often administered intravenously and are hence distributed all through the body and adsorbed by serum proteins, erythrocytes, or by other cells that also have a high division rate (Bagnyukova et al., 2010; Shields, 2017; O'Halloran et al., 2019), such as gastrointestinal epithelial cells, hair follicles, etc., leaving a minimum effective concentration delivered in the tumor site (Aslam et al., 2014; Bryer and Henry, 2018; Zia et al., 2018; Dewhirst et al., 2019; Haslam and Smart, 2019). In consequence, the treatment complications implicate a decrease in the patient's quality of life (Nurgali et al., 2018). In addition, drug characteristics can develop treatment failures, such as a lack of specificity by cancer cells (non-targeted molecules), accumulation in healthy organs, and the resistance mechanisms that tumor cells acquire, e.g., apoptosis suppression, altering drug metabolism, epigenetic regulation, alteration of drug targets, and enhanced DNA repair and gene amplification (Mansoori et al., 2017; Zugazagoitia et al., 2016).

To overcome these limitations, strategies based on drug delivery systems (DDSs) have been created. These techniques are based on organic, inorganic, and polymeric materials resulting in nanocarriers (NC) like liposomes, micelles, nanoparticles (NPs), dendrimers Tiwari et al., 2012; 

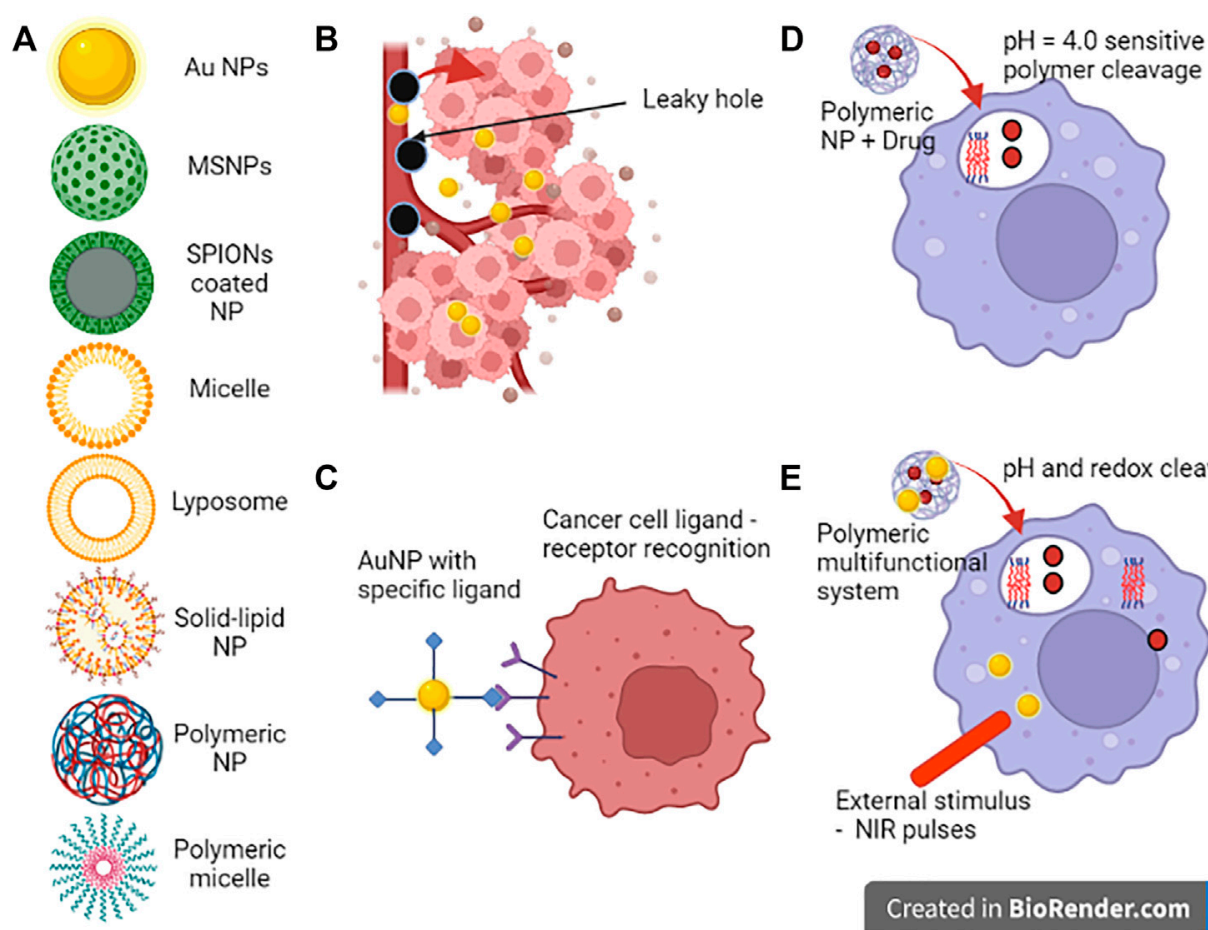

C

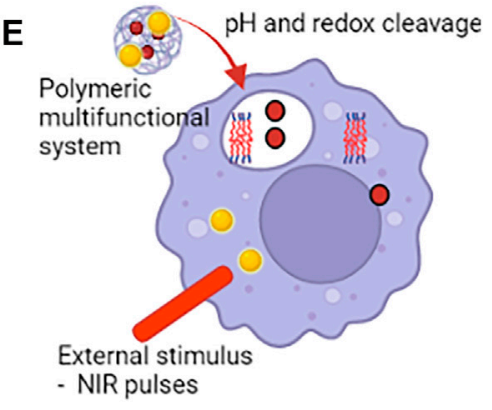

Created in BioRender.com bio

FIGURE 1 | Smart drug delivery strategies, (A) devices, (B) passive, and (C) active delivery, and (D) single and (E) multifunctional stimuli.

Fonseca et al., 2015; Mu et al., 2020. Using them in a simplistic manner, these strategies only depend on the passive delivery, such as the intravenous administration, enhanced permeability and retention effect (EPR), and response of the carrier in the tumor microenvironment. Nevertheless, with the advances in materials technology, these strategies can be improved by chemical or physical functionalization, active targeting of cancer cell biomarkers, design, and engineering for single or multifunctional stimuli-responsive NCs.

However, the resulting NCs have limitations and disadvantages when the in vitro to in vivo transition occurs. These challenges involve the initial or latter size of the carrier when it interacts with the systemic fluids and molecules, tumor microenvironment, the physiological barriers, the cell uptake pathway, and the complexity of the design (chemical conjugation, core, shell, multifunction) thinking in great scale manufacturing.

This mini review focuses on the fundamentals of strategies of the DDS, and the advantages and disadvantages of single or multifunctional stimuli and the challenges.

\section{Drug Delivery Systems}

The DDSs (Figure 1A) are platforms at the micro- and nanometer scale whose design allows to contain and release substances (drugs, imaging dyes, stimuli sensitizers, and macromolecules) with greater efficacy than regular treatment and to decrease adverse effects on other healthy organs or tissues, as well as improve pharmaceutical adherence and the quality of life of patients. The administration of a DDSs in in vivo cancer models has been used in intravenous, intra-tumor, and localized manner (Patra et al., 2018; Sharma, 2019). These strategies are based on organic, inorganic, and polymeric materials (Kamareddine et al., 2019). The organic NCs are composed by phospholipids, carbohydrates, and nucleic acids, forming, e.g., micelles and liposomes, which can encapsulate drugs or activate molecules depending on their charge or their hydrophobic or hydrophilic behavior (LópezDávila et al., 2012).

Inorganic material DDSs include metallic core or metallic core-shell gold NPs, quantum dots, superparamagnetic ironoxide NPs (SPIONs), mesoporous silica particles, and nanovaccines (Kumar et al., 2020a; Machhi et al., 2021). Unlike organic based NCs, an intrinsic antineoplastic effect, although the effect can also be enhanced by loading drugs inside them, in their pores, or adsorbed on to their surface (Ghosn et al., 2019; Shi et al., 2020a). Hydrogels, NPs, fibers, dendrimers, and micelles can be made based on polymers (synthetic and natural). These are carriers of hydrophobic molecules, as are many of the chemotherapeutic agents, and biodegradable polymers that can have responsive characteristics to stimuli such as $\mathrm{pH}$ difference, redox environment, or being thermolabile at low temperatures (Wen et al., 2018). The combinations of these materials or delivery systems can be processed to change the administration or to load other types of molecules that their initial chemical nature restricts.

The investigation in this field of NCs is limited to in vitro and in vivo studies. Future sites of bioaccumulation of metallic NCs 
and nonbiodegradable polymers can develop even more toxicity or immunogenicity than the carried molecule itself.

\section{Types of Strategies}

To improve the DDS, the composition inside and outside of them needs to be functionalized, thus adsorption of new molecules will increase delivery to the tumor sites, the cellular uptake, and the controlled release of the substances. Firstly, the DDS can be delivered to the tumor site in two patterns: passive and active (Figures 1B,C; Senapati et al., 2018; Kumar et al., 2020b).

\section{Passive Delivery (Enhanced Permeability and Retention Effect)}

Passive delivery requires EPR that includes two phenomena. Firstly, the tumor mass starts to grow in a localized spot and needs new blood vessels that can provide it with nutrients and oxygen, so the cancer cells release growth factors and hormones to build them; this process is called angiogenesis. The consequence of the rapid construction of these blood vessels are the leaky holes $(100-800 \mathrm{~nm})$, through which the delivery systems can pass by an extravasation process. Secondly, the tumor environment has a deficient lymphatic system, thus the accumulation of the delivery systems has more concentration here than in healthy organs or tissues, and as a result of this, there is an increased cellular uptake and release into the cellular cytoplasm having enhanced toxicity in cancer cells (Alavi and Hamidi, 2019; Kalyane et al., 2019; Shi et al., 2020b). The weak spot in passive delivery is the implication of the retention only in tumor sites it implicates only the retention in tumor sites (solid tumors); however, there is a lack of such an affinity when liquid tumor or metastasis cancer cells tend to be treated. To overcome this issue, a better approach is required, with the solution being active delivery.

\section{Active Delivery (Ligand-Receptor)}

Active delivery stands for modifications made to delivery strategies on their surfaces (Fang et al., 2011). Molecules adsorbed on the carrier's surface provide higher affinity because of the differences at the plasmatic membrane level in the number of receptors that are overexpressed, expressed, or absent in cancer cells that can lead to enhanced cellular uptake (Danhier et al., 2010; Bazak et al., 2014; Kumari et al., 2015; Nag and Delehanty, 2019; Zhao et al., 2020). Despite this, it has been observed that these systems are more efficient in in vitro assays than in vivo, and this phenomenon can be explained by two mechanisms; firstly, the tumor environment has reduced permeation that can exist in the central parts of the tumor, such that their activity is only observed in the places closest to the deficient veins, although because the administration is systemic, but active delivery NCs can trace metastatic cancer cells if this are in the blood circulation or lymph nodes (Pearce and O'Reilly, 2019), and secondly, the aggregation of the spectra of molecules and macromolecules in the vascular system (complement proteins, albumin, etc.) in the in vivo model that can bind to the surface making a corona, increasing their size, hiding the target particles, or being easily cleared by their diminishing the affinity for the receptors in the cancer cells.
The molecules that have helped guide the DDS are divided in a general way as small molecules and biomolecules. Conforming to the small molecule group is folic acid, lectin, glucophosphamide, argininyl-glycinyl-aspartic acid (RGD) (Sundararaj et al., 2016). The biomolecules, that can be attached by functionalization of the NC surfaces are antibodies, transferrin, peptides, aptamers (single-chain nucleotide sequences) (Sun et al., 2014; Kue et al., 2016; Li et al., 2020). The disadvantages found in the active delivery are the corona formation in in vivo models and the lysosome or endosome escape that could lead to an inactivation of the drugs or macromolecules in the carriers. Therefore, the efficacy of the strategies' delivery, when administered intravenously, will depend on passive delivery and further enhanced performance of internalization of the systems due to the interaction with ligands (active).

\section{Single Function or Multifunction}

Another way to improve the delivery strategies is by adding functions, and these will depend on the chemical nature of the components and how they react with the environment, whether in the bloodstream, the tumor environment, tissues, or organs. The single function and multifunction DDS (Figures 1D,E) rely on the behavior of the materials specifically designed to react to the chemical and biological changes that exist in the tumor environment (Montaño-Samaniego et al., 2020).

\section{Single Function}

The DDS with a single functional release depends on internal stimuli (e.g., redox potential $\mathrm{pH}$, enzymes), which means the influence of the different characteristics of the tumor microenvironment in contrast to a healthy tissue or organ environment (Mi, 2020) that will dissolve or collapse the NCs. The changes in $\mathrm{pH}$ in the tumor microenvironment ( $\mathrm{pH}, 6.5-6.8)$ and in the lysosomes/endosomes $(\mathrm{pH}, 4-6) \mathrm{can}$ be applied to control the release of drugs in The differences, in contrast of healthy cells, the lower $\mathrm{pH}$ in tumor microenvironment., moreover, the oxidation-reduction reactions (redox) are enhanced, attributed to the higher concentration of reduced glutathione (GSH) in cancer cells $(0.5-10 \mathrm{mM})$ than in healthy cells (2-20 Um) (GSH) has higher levels inside cancer cells $(0.5-10 \mathrm{mM})$ in contrast to healthy cells $(2-20 \mu \mathrm{M})$. Disulfide (S-S) and diselenide ( $\mathrm{Se}-\mathrm{Se}$ ) bonds are functionalized in the NC surface to be cleaved by GSH. In addition, some DDSs respond to $\mathrm{H}_{2} \mathrm{O}_{2}$ concentrations to treat hypoxic and multidrug-resistant tumors (Hirata and Sahai, 2017; Wu and Dai, 2017; Qiao et al., 2019; Arneth, 2020).

Moreover, some ligands are responsive to enzymatic reactions like activation, degradation or dissociation of hydroxyl bonds, direct cleavage of the carrier and controlled release, due to higher concentration of oxiderectuctases, transferass and hydrolases. (Ji et al., 2019).

\section{Multifunction}

The DDSs that already have a single function can be conjugated with sensitive molecules that react to external stimulus, creating a multifunctional strategy. The external stimuli include magnetic, electric, ultrasound, and infrared light. These stimuli help the 
TABLE 1 | Single and multifunctional strategies for intravenous administration in in vivo models.

\begin{tabular}{|c|c|c|c|c|c|}
\hline Device & Load & Target molecule & $\begin{array}{l}\text { Single function } \\
\text { or multifunction }\end{array}$ & Results & References \\
\hline $\begin{array}{l}\text { High-density } \\
\text { lipoprotein like }\end{array}$ & $\begin{array}{l}\text { DCA } \\
\text { p53 }\end{array}$ & $\begin{array}{l}\text { Anisamide } \\
\text { ApoA-I }\end{array}$ & Single $(\mathrm{pH})$ & $\begin{array}{l}\text { Tumor volume decreased in a } 6.7 \text { factor. Human pulmonary } \\
\text { adenocarcinoma }\end{array}$ & Shirata et al. (2017) \\
\hline Gold NP & DOX & - & Single $(p H)$ & $\begin{array}{l}\text { Decrease of tumor volume in a } 1.5 \text { factor, less variation of mice } \\
\text { weight, thus, security in major organs }\end{array}$ & Lee et al. (2017) \\
\hline Polymeric NP & DOX & $\begin{array}{l}\text { GA } \\
\text { Lactobionic acid }\end{array}$ & Single $(\mathrm{pH})$ & $\begin{array}{l}\text { Greater intake of the NPs with both targeting ligands, no damage in } \\
\text { the kidney and heart }\end{array}$ & $\begin{array}{l}\text { Arafa and } \\
\text { El-sherbiny (2020) }\end{array}$ \\
\hline Polymeric micelle & $\begin{array}{l}\text { PTX } \\
\text { Vit E }\end{array}$ & $\begin{array}{l}\text { Hyaluronic acid } \\
\text { Folic acid }\end{array}$ & Single (redox) & $\begin{array}{l}\text { The micelles distribution is in the heart, lungs, kidneys, and tumor, } \\
\text { the last with the major amount. Tumor volume decreased } 40 \text { times its } \\
\text { size. The weight of the mice didn't change with the treatment with the } \\
\text { micelles, indicating lack of damage in major organs }\end{array}$ & Zhang et al. (2016) \\
\hline Hemiporous silica NP & DOX & Poly-L-lysine & Multi (pH/redox) & $\begin{array}{l}\text { Tumor weight decreased in a factor of } 5.6 \text {, mice weight showed no } \\
\text { variations; although, the device had more half a lifetime }\end{array}$ & Yang et al. (2020) \\
\hline Polymeric NP & DTX & Chondroitin sulfate & $\begin{array}{l}\text { Multi (redox/ } \\
\text { enzyme) }\end{array}$ & $\begin{array}{l}\text { Lung metastasis model in B16F10 mice, the distribution at } 12 \mathrm{~h} \text { was } \\
\text { major in the liver, but in comparison to free DTX, the amount of device } \\
\text { DTX was higher in the lungs and tumor tissue. It led to a growth } \\
\text { inhibition of } 85 \% \text { and a reduction of metastatic nodules by } 51 \%\end{array}$ & Wang et al. (2018) \\
\hline Gold nanorods & DOX & - & Multi $(\mathrm{pH}, \mathrm{PT})$ & $\begin{array}{l}\text { The device with laser stimulation had a tumor decrease starting at } \\
\text { day 2, from } 130 \mathrm{~mm}^{3} \text { to almost } 0 \mathrm{~mm}^{3} \text { for the } 15 \text { days of treatment, } \\
\text { recovering from the disease without tumor recurrence in } 60 \text { days } \\
\text { after treatment. Free DOX tumor treatment increased in volume to } \\
700 \mathrm{~mm}^{3}\end{array}$ & Liu et al. (2018) \\
\hline
\end{tabular}

NP, Nanoparticle; DCA, dichloroacetate; DOX, Doxorubicin; VR, Vinorelbine; PTX, Paclitaxel; VitE, Vitamin E; ICG, indocyanine green; DTX, Docetaxel; GA, 18 - glycyrrhetinic acid; PT, photothermal; MDR, multidrug resistance.

DDS have greater accumulation at the tumor site (magnetically guided), controlled release, thermal damage, and imaging (Cheng et al., 2013; Yao et al., 2016; Lee and Thompson, 2017; Li et al., 2019; Zhang et al., 2019). The major advantage of using a DDS with multifunction is to precisely control the release according to the intensity and time of the external stimulus (Singh et al., 2017). Ultrasound works through high-frequency waves, which serves for imaging purposes (frequencies $<20 \mathrm{~Hz}$ ) or to break the DDS or increase cell membrane permeability (frequencies $>20 \mathrm{~Hz}$ ) (Alsawaftah et al., 2021).

Temperature-sensitive materials as the DDS and therapy. They are usually made to have their effect at a normal body temperature of $37^{\circ} \mathrm{C}$ and are sensitive at higher temperatures $\left(>40^{\circ} \mathrm{C}\right)$ with significant changes leading to drug release. Thermoresponsive polymers (Pluronic F-127, poly (Nisopropylacrylamide) and molecules that react to hyperthermia treatment $\left(\mathrm{NH}_{4} \mathrm{HCO}_{3}\right)$ (Wang et al., 2016) can be used.

It is also possible to design a DDS responsive to an induced magnetic field, which can be active targeted as well as having the property to perform hyperthermic therapy in response to the exertion of the magnetic field. exerting a magnetic field. They are mostly made with SPIONs, magnetite $\left(\mathrm{Fe}_{3} \mathrm{O}_{4}\right)$, and maghemite $\left(\mathrm{Fe}_{2} \mathrm{O}_{3}\right)$ that are often conjugated for this purpose (Gomes et al., 2019; Liu et al., 2020). Finally, molecules in a DDS can be stimulated by UV-Vis radiation, less used because of clinical implications, and near infrared spectrum (NIR) light, NIR is used for four reasons: 1) depth of tissue penetration $(\sim 1 \mathrm{~cm}) ; 2)$ to avoid unexpected absorption of energy by tissues, blood hemoglobin, or water; 3) strong absorption of gold, carbon, or $\mathrm{CuS}$ materials for photothermal or photodynamic therapies, and 4) minimal phototoxicity therefore appropriate for clinical use (Bao et al., 2016; Fatima et al., 2021). In addition, it controls the release of drugs and can generate the oxygen singlet $\left(\mathrm{O}_{2}{ }^{1}\right)$, leading to the production of reactive oxygen species (ROS) and thus tumor damage (Guerrero-Florez et al., 2020; Wang et al., 2020).

The examples of devices made to rely on a single or multifunctional stimuli are listed in Table $\mathbf{1}$.

Multifunction DDSs can be combined to be sensitive to more than two stimuli. A multifunction DDS (Lu et al. (2020)) based in $\mathrm{pH}, \mathrm{GSH}$ and NIR stimuliresponsive MSNPs, such as, $\mathrm{pH}, \mathrm{GSH}$ and NIR, MSNPs coated with carbon NPs for drug delivery of Doxorubicin and photothermal therapy which in 15 days the DDS exhibited superior antitumor effect with the NIR pulses and safety than de free DOX group, although the DDS had low drug loading capacity (Chen et al., 2018). The disadvantages are presented in the case of metastatic lesions, where the metastatic tumor foci are not completely localized, therefore, the systems sensitive to stimuli from the tumor 
microenvironment will not be able to function correctly because of the mistaken place of the external stimuli. Furthermore, multifunctional strategies have a higher level of complexity in the design, process, and manufacturing developments.

\section{CONCLUSION}

The design of smart drug delivery strategies has proven to be effective against solid and metastatic tumors in in vivo models. Carriers with active delivery enhance the affinity and cellular uptake, in addition, single function or multifunction DDS exhibits an

\section{REFERENCES}

Alavi, M., and Hamidi, M. (2019). Passive and Active Targeting in Cancer Therapy by Liposomes and Lipid Nanoparticles. Drug Metab. Pers. Ther. 34, 1-8. doi:10.1515/dmpt-2018-0032

Alsawaftah, N., Pitt, W. G., and Husseini, G. A. (2021). Dual-Targeting and Stimuli-Triggered Liposomal Drug Delivery in Cancer Treatment. ACS Pharmacol. Transl. Sci. 4, 1028-1049. doi:10.1021/acsptsci.1c00066

Arafa, K., and El-sherbiny, I. M. (2020). Dual-Ligand Functionalized Core-Shell Chitosan-Based Nanocarrier for Hepatocellular Carcinoma-Targeted Drug Delivery. Int. J. Nanomed. 15, 821-837. doi:10.2147/IJN.S240359

Arneth, B. (2020). Tumor Microenvironment. Medicina 56, 15. doi:10.3390/ medicina56010015

Aslam, M. S., Naveed, S., Ahmed, A., Abbas, Z., Gull, I., and Athar, M. A. (2014). Side Effects of Chemotherapy in Cancer Patients and Evaluation of Patients Opinion About Starvation Based Differential Chemotherapy. J. Cancer Ther. 05, 817-822. doi:10.4236/jct.2014.58089

Bagnyukova, T. V., Serebriiskii, I. G., Zhou, Y., Hopper-borge, E. A., Golemis, E. A., and Astsaturov, I. (2010). Chemotherapy and Signaling. Cancer Biol. Ther. 10, 839-853. doi:10.4161/cbt.10.9.13738

Bao, Z., Liu, X., Liu, Y., Liu, H., and Zhao, K. (2016). Near-Infrared LightResponsive Inorganic Nanomaterials for Photothermal Therapy. Asian J. Pharm. Sci. 11 (3), 349-364. doi:10.1016/j.ajps.2015.11.123

Bazak, R., Houri, M., El Achy, S., Kamel, S., and Refaat, T. (2014). Cancer Active Targeting by Nanoparticles: a Comprehensive Review of Literature. J. Cancer Res. Clin. Oncol. 141, 769-784. doi:10.1007/ s00432-014-1767-3

Bryer, E., and Henry, D. (2018). Chemotherapy-induced Anemia: Etiology, Pathophysiology, and Implications for Contemporary Practice. Int. J. Clin. Transfus. Med. 6, 21-31. doi:10.2147/ijctm.s187569

Chen, J., Li, X., Zhao, X., Wu, Q., Zhu, H., Mao, Z., et al. (2018). DoxorubicinConjugated $\mathrm{pH}$-Responsive Gold Nanorods for Combined Photothermal Therapy and Chemotherapy of Cancer. Bioactive Mater. 3 (3), 347-354. doi:10.1016/j.bioactmat.2018.05.003

Chen, Z., Wan, L., Yuan, Y., Kuang, Y., Xu, X., Liao, T., et al. (2020). pH/GSHDual-Sensitive Hollow Mesoporous Silica Nanoparticle-Based Drug Delivery System for Targeted Cancer Therapy. ACS Biomater. Sci. Eng. 6, 3375-3387. doi:10.1021/acsbiomaterials.0c00073

Cheng, R., Meng, F., Deng, C., Klok, H.-A., and Zhong, Z. (2013). Dual and MultiStimuli Responsive Polymeric Nanoparticles for Programmed Site-specific Drug Delivery. Biomaterials 34 (14), 3647-3657. doi:10.1016/ j.biomaterials.2013.01.084

Danhier, F., Feron, O., and Préat, V. (2010). To Exploit the Tumor Microenvironment: Passive and Active Tumor Targeting of Nanocarriers for Anti-Cancer Drug Delivery. J. Control. Release 148 (2), 135-146. doi:10.1016/ j.jconrel.2010.08.027

Dewhirst, M. W., Secomb, T. W., and Carolina, N. (2019). Transport of Drugs from Blood Vessels to Tumour Tissue. Nat. Rev. Cancer 17 (12), 738-750. doi:10.1038/nrc.2017.93.Transport enhanced effect of controlled release, with fewer or no adverse effects observed in healthy major organs, in contrast to regular chemotherapeutic agents. Despite innovations, there are still challenges that include endosome escape, lysosome degradation, corona formation, complex design and engineering which can impact in the cost of the therapy, which have to be overcome in future research to be evaluating in clinical trials.

\section{AUTHOR CONTRIBUTIONS}

CL and LA conceptualized and wrote the manuscript.

Fang, J., Nakamura, H., and Maeda, H. (2011). The EPR Effect: Unique Features of Tumor Blood Vessels for Drug Delivery, Factors Involved, and Limitations and Augmentation of the Effect. Adv. Drug Deliv. Rev. 63 (3), 136-151. doi:10.1016/ j.addr.2010.04.009

Fatima, H., Charinpanitkul, T., and Kim, K.-S. (2021). Fundamentals to Apply Magnetic Nanoparticles for Hyperthermia Therapy. Nanomaterials 11 (5), 1203. doi:10.3390/nano11051203

Fonseca, A. C., Serra, A. C., and Coelho, J. F. J. (2015). Bioabsorbable Polymers in Cancer Therapy: Latest Developments. EPMA J. 6 (1), 1-18. doi:10.1186/ s13167-015-0045-Z

Ghosn, Y., Kamareddine, M. H., Tawk, A., Elia, C., El Mahmoud, A., Terro, K., et al. (2019). Inorganic Nanoparticles as Drug Delivery Systems and Their Potential Role in the Treatment of Chronic Myelogenous Leukaemia. Technol. Cancer Res. Treat. 18, 153303381985324. doi:10.1177/1533033819853241

Gong, Z., Chen, M., Ren, Q., Yue, X., and Dai, Z. (2020). Fibronectin-Targeted Dual-Acting Micelles for Combination Therapy of Metastatic Breast Cancer. Sig Transduct Target. Ther. 5, 12. doi:10.1038/s41392-019-0104-3

Guerrero-Florez, V., Mendez-Sanchez, S. C., Patrón-Soberano, O. A., RodríguezGonzález, V., Blach, D., and Martínez O., F. (2020). Gold NanoparticleMediated Generation of Reactive Oxygen Species during Plasmonic Photothermal Therapy: A Comparative Study for Different Particle Sizes, Shapes, and Surface Conjugations. J. Mater. Chem. B 8 (14), 2862-2875. doi:10.1039/d0tb00240b

Haslam, I. S., and Smart, E. (2019). Chemotherapy-Induced Hair Loss: The Use of Biomarkers for Predicting Alopecic Severity and Treatment Efficacy. Biomark Insights 14, 117727191984218. doi:10.1177/1177271919842180

Hirata, E., and Sahai, E. (2017). Tumor Microenvironment and Differential Responses to Therapy. Cold Spring Harb. Perspect. Med. 7, a026781. doi:10.1101/cshperspect.a026781

Kamareddine, M. H., Ghosn, Y., Tawk, A., Elia, C., Alam, W., Makdessi, J., et al. (2019). Organic Nanoparticles as Drug Delivery Systems and Their Potential Role in the Treatment of Chronic Myeloid Leukemia. Technol. Cancer Res. Treat. 18, 153303381987990. doi:10.1177/1533033819879902

Ji, K., Mayernik, L., Moin, K., and Sloane, B. F. (2019). Acidosis and Proteolysis in the Tumor Microenvironment. Cancer Metastasis Rev. 38, 103-112. doi:10.1007/s10555-019-09796-3

Kalyane, D., Raval, N., Maheshwari, R., Tambe, V., Kalia, K., and Tekade, R. K. (2019). Employment of Enhanced Permeability and Retention Effect (EPR): Nanoparticle-Based Precision Tools for Targeting of Therapeutic and Diagnostic Agent in Cancer. Mater. Sci. Eng. C Mater Biol. Appl. 98, 1252-1276. doi:10.1016/j.msec.2019.01.066

Kue, C. S., Kamkaew, A., Burgess, K., Kiew, L. V., Chung, L. Y., and Lee, H. B. (2016). Small Molecules for Active Targeting in Cancer. Med. Res. Rev. 36 (3), 494-575. doi:10.1002/med.21387

Kumar, R., Dalvi, S. V., and Siril, P. F. (2020). Nanoparticle-Based Drugs and Formulations: Current Status and Emerging Applications. ACS Appl. Nano Mater. 3, 4944-4961. doi:10.1021/acsanm.0c00606

Kumar, R., Mondal, K., Panda, P. K., Kaushik, A., Abolhassani, R., Ahuja, R., et al. (2020). Core-shell Nanostructures: Perspectives towards Drug Delivery Applications. J. Mater. Chem. B 8 (39), 8992-9027. doi:10.1039/d0tb01559h 
Kumari, P., Ghosh, B., and Biswas, S. (2015). Nanocarriers for Cancer-Targeted Drug Delivery. J. Drug Target. 24 (00), 179-191. doi:10.3109/ 1061186X.2015.1051049

Lee, C.-S., Kim, H., Yu, J., Yu, S. H., Ban, S., Oh, S., et al. (2017). DoxorubicinLoaded Oligonucleotide Conjugated Gold Nanoparticles: A Promising In Vivo Drug Delivery System for Colorectal Cancer Therapy. Eur. J. Med. Chem. 142, 416-423. doi:10.1016/j.ejmech.2017.08.063

Lee, Y., and Thompson, D. H. (2017). Stimuli-Responsive Liposomes for Drug Delivery. WIREs Nanomed. Nanobiotechnol. 9 (5), 1-76. doi:10.1002/ wnan. 1450

Li, J., Eu, J. Q., Kong, L. R., Wang, L., Lim, Y. C., Goh, B. C., et al. (2020). Targeting Metabolism in Cancer Cells and the Tumour Microenvironment for Cancer Therapy. Molecules 25 (20), 4831-4840. doi:10.3390/molecules25204831

Li, L., Yang, W.-W., and Xu, D.-G. (2019). Stimuli-Responsive Nanoscale Drug Delivery Systems for Cancer Therapy. J. Drug Target. 27, 423-433. doi:10.1080/ 1061186X.2018.1519029

Liu, M., Du, H., Khan, A. R., Ji, J., Yu, A., and Zhai, G. (2018). Redox/Enzyme Sensitive Chondroitin Sulfate-Based Self-Assembled Nanoparticles Loading Docetaxel for the Inhibition of Metastasis and Growth of Melanoma. Carbohydr. Polym. 184, 82-93. doi:10.1016/j.carbpol.2017.12.047

Liu, X., Zhang, Y., Wang, Y., Zhu, W., Li, G., Ma, X., et al. (2020). Comprehensive Understanding of Magnetic Hyperthermia for Improving Antitumor Therapeutic Efficacy. Theranostics 10 (8), 3793-3815. doi:10.7150/thno.40805

López-Dávila, V., Seifalian, A. M., and Loizidou, M. (2012). Organic Nanocarriers for Cancer Drug Delivery. Curr. Opin. Pharmacol. 12, 414-419. doi:10.1016/ j.coph.2012.02.011

Lu, H., Zhao, Q., Wang, X., Mao, Y., Chen, C., Gao, Y., et al. (2020). Multi-Stimuli Responsive Mesoporous Silica-Coated Carbon Nanoparticles for ChemoPhotothermal Therapy of Tumor. Colloids Surf. B Biointerf. 190, 110941. doi:10.1016/j.colsurfb.2020.110941

Machhi, J., Shahjin, F., Das, S., Patel, M., Abdelmoaty, M. M., Cohen, J. D., et al. (2021). Nanocarrier Vaccines for SARS-CoV-2. Adv. Drug Deliv. Rev. 171, 215-239. doi:10.1016/j.addr.2021.01.002

Mansoori, B., Mohammadi, A., Davudian, S., Shirjang, S., and Baradaran, B. (2017). The Different Mechanisms of Cancer Drug Resistance: A Brief Review. Adv. Pharm. Bull. 7 (3), 339-348. doi:10.15171/apb.2017.041

Mi, P. (2020). Stimuli-Responsive Nanocarriers for Drug Delivery, Tumor Imaging, Therapy and Theranostics. Theranostics 10 (10), 4557-4588. doi:10.7150/thno.38069

Montaño-Samaniego, M., Bravo-Estupiñan, D. M., Méndez-Guerrero, O., Alarcón-Hernández, E., and Ibáñez-Hernández, M. (2020). Strategies for Targeting Gene Therapy in Cancer Cells With Tumor-Specific Promoters. Front. Oncol. 10, 1-18. doi:10.3389/fonc.2020.605380

Mu, W., Chu, Q., Liu, Y., and Zhang, N. (2020). A Review on Nano-Based Drug Delivery System for Cancer Chemoimmunotherapy. Nano-Micro Lett. 12 (1), 1-24. doi:10.1007/s40820-020-00482-6

Nag, O. K., and Delehanty, J. B. (2019). Active Cellular and Subcellular Targeting of Nanoparticles for Drug Delivery. Pharmaceutics 11, 543-549. doi:10.3390/ pharmaceutics 11100543

Nurgali, K., Jagoe, R. T., and Abalo, R. (2018). Editorial: Adverse Effects of Cancer Chemotherapy: Anything New to Improve Tolerance and Reduce Sequelae? Front. Pharmacol. 9, 1-3. doi:10.3389/fphar.2018.00245

O'Halloran, N., Lowery, A., Curran, C., McLaughlin, R., Malone, C., Sweeney, K., et al. (2019). A Review of the Impact of Neoadjuvant Chemotherapy on Breast Surgery Practice and Outcomes. Clin. Breast Cancer 19 (5), 377-382. doi:10.1016/j.clbc.2019.04.011

Patra, J. K., Das, G., Fraceto, L. F., Campos, E. V. R., Rodriguez-Torres, M. d. P., Acosta-Torres, L. S., et al. (2018). Nano Based Drug Delivery Systems: Recent Developments and Future Prospects. J. Nanobiotechnol 16, 1-33. doi:10.1186/ s12951-018-0392-8

Pearce, A. K., and O'Reilly, R. K. (2019). Insights into Active Targeting of Nanoparticles in Drug Delivery: Advances in Clinical Studies and Design Considerations for Cancer Nanomedicine. Bioconjug. Chem. 30, 2300-2311. doi:10.1021/acs.bioconjchem.9b00456

Gomes, I. P., Aparecida Duarte, J., Chaves Maia, A. L., Rubello, D., Townsend, D. M., Branco de Barros, A. L., et al. (2019). Thermosensitive Nanosystems Associated with Hyperthermia for Cancer Treatment. Pharmaceuticals 12 (4), 171. doi:10.3390/ph12040171
Qiao, Y., Wan, J., Zhou, L., Ma, W., Yang, Y., Luo, W., et al. (2019). StimuliResponsive Nanotherapeutics for Precision Drug Delivery and Cancer Therapy. WIREs Nanomed Nanobiotechnol. 11 (1), 1-20. doi:10.1002/wnan.1527

Senapati, S., Mahanta, A. K., Kumar, S., and Maiti, P. (2018). Controlled Drug Delivery Vehicles for Cancer Treatment and Their Performance. Sig Transduct Target. Ther. 3 (1), 1-19. doi:10.1038/s41392-017-0004-3

Sharma, M. (2019). "Chapter 18 - Transdermal and Intravenous Nano Drug Delivery Systems: Present and Future," in Applications of Targeted Nano Drugs and Delivery Systems (Amsterdam: Elsevier), 499-550. doi:10.1016/B978-0-12814029-1.00018-1

Shi, Y., van der Meel, R., Chen, X., and Lammers, T. (2020). The EPR Effect and Beyond: Strategies to Improve Tumor Targeting and Cancer Nanomedicine Treatment Efficacy. Theranostics 10 (17), 7921-7924. doi:10.7150/ thno.49577

Shi, Z., Zhou, Y., Fan, T., Lin, Y., Zhang, H., and Mei, L. (2020). Inorganic NanoCarriers Based Smart Drug Delivery Systems for Tumor Therapy. Smart Mater. Med. 1, 32-47. doi:10.1016/j.smaim.2020.05.002

Shields, M. (2017). Chemotherapeutics. Pharmacognosy 295-313. doi:10.1016/ B978-0-12-802104-0.00014-7

Shirata, C., Kaneko, J., Inagaki, Y., Kokudo, T., Sato, M., Kiritani, S., et al. (2017). Near-Infrared Photothermal/Photodynamic Therapy with Indocyanine Green Induces Apoptosis of Hepatocellular Carcinoma Cells through Oxidative Stress. Sci. Rep. 7 (1), 1-8. doi:10.1038/s41598-017-14401-0

Singh, B., Khurana, R. K., Garg, B., Saini, S., and Kaur, R. (2017). StimuliResponsive Systems with Diverse Drug Delivery and Biomedical Applications: Recent Updates and Mechanistic Pathways. Crit. Rev. Ther. Drug Carrier Syst. 34 (3), 209-255. doi:10.1615/ CritRevTherDrugCarrierSyst.2017017284

Sun, T., Zhang, Y. S., Pang, B., Hyun, D. C., Yang, M., and Xia, Y. (2014). Engineered Nanoparticles for Drug Delivery in Cancer Therapy. Angew. Chem. Int. Ed. 53 (46), 12320-12364. doi:10.1002/anie.201403036

Sundararaj, S. C., Al-Sabbagh, M., Rabek, C. L., Dziubla, T. D., Thomas, M. V., and Puleo, D. A. (2016). Comparison of Sequential Drug Release In Vitro and In Vivo. J. Biomed. Mater. Res. 104 (7), 1302-1310. doi:10.1002/ jbm.b.33472

Tiwari, G., Tiwari, R., Bannerjee, S., Bhati, L., Pandey, S., Pandey, P., et al. (2012). Drug Delivery Systems: An Updated Review. Int. J. Pharma Investig. 2 (1), 2. doi:10.4103/2230-973X.96920

Wang, J., Mi, P., Lin, G., Wáng, Y. X. J., Liu, G., and Chen, X. (2016). ImagingGuided Delivery of RNAi for Anticancer Treatment. Adv. Drug Deliv. Rev. 104, 44-60. doi:10.1016/j.addr.2016.01.008

Wang, M., Wu, J., Li, Y., Li, F., Hu, X., Wang, G., et al. (2018). A Tumor Targeted Near-Infrared Light-Controlled Nanocomposite to Combat with Multidrug Resistance of Cancer. J. Control. Release 288, 34-44. doi:10.1016/ j.jconrel.2018.08.037

Wen, R., Umeano, A. C., Chen, P., and Farooqi, A. A. (2018). Polymer-Based Drug Delivery Systems for Cancer. Crit. Rev. Ther. Drug Carrier Syst. 35 (6), 521-553. doi:10.1615/CritRevTherDrugCarrierSyst.2018021124

$\mathrm{Wu}, \mathrm{T}$., and Dai, Y. (2017). Tumor Microenvironment and Therapeutic Response. Cancer Lett. 387, 61-68. doi:10.1016/j.canlet.2016.01.043

Wang, X., Xuan, Z., Zhu, X., Sun, H., Li, J., Xie, Z., et al. (2020). Near-Infrared Photoresponsive Drug Delivery Nanosystems for Cancer PhotoChemotherapy. J. Nanobiotechnology 18, 108-119. doi:10.1186/s12951-02000668-5

Yang, Y., Li, Y., Chen, K., Zhang, L., Qiao, S., Tan, G., et al. (2020). Dual ReceptorTargeted and Redox-Sensitive Polymeric Micelles Self-Assembled from a Folic Acid-Hyaluronic Acid-SS-Vitamin E Succinate Polymer for Precise Cancer Therapy. Int. J. Nanomedicine 15, 2885-2902. doi:10.2147/IJN.S249205

Yao, J., Feng, J., and Chen, J. (2016). External-Stimuli Responsive Systems for Cancer Theranostic. Asian J. Pharm. Sci. 11 (5), 585-595. doi:10.1016/ j.ajps.2016.06.001

Zhang, F., Li, M., Su, Y., Zhou, J., and Wang, W. (2016). A Dual-Targeting Drug Co-delivery System for Tumor Chemo- and Gene Combined Therapy. Mater. Sci. Eng. C 64, 208-218. doi:10.1016/j.msec.2016.03.083

Zhang, Z.-T., Huang-Fu, M.-Y., Xu, W.-H., and Han, M. (2019). StimulusResponsive Nanoscale Delivery Systems Triggered by the Enzymes in the Tumor Microenvironment. Eur. J. Pharm. Biopharm. 137, 122-130. doi:10.1016/j.ejpb.2019.02.009 
Zhao, Z., Ukidve, A., Kim, J., and Mitragotri, S. (2020). Targeting Strategies for Tissue-Specific Drug Delivery. Cell 181 (1), 151-167. doi:10.1016/ j.cell.2020.02.001

Zia, M. K., Siddiqui, T., Ali, S. S., Rehman, A. A., Ahsan, H., and Khan, F. H. (2018). Chemotherapeutic Drugs and Plasma Proteins: Exploring New Dimensions. Curr. Protein Pept. Sci. 19, 937-947. doi:10.2174/1389203718666171002115547

Zugazagoitia, J., Guedes, C., Ponce, S., Ferrer, I., Molina-Pinelo, S., and Paz-Ares, L. (2016). Current Challenges in Cancer Treatment. Clin. Ther. 38 (7), 1551-1566. doi:10.1016/j.clinthera.2016.03.026

Conflict of Interest: The authors declare that the research was conducted in the absence of any commercial or financial relationships that could be construed as a potential conflict of interest.
Publisher's Note: All claims expressed in this article are solely those of the authors and do not necessarily represent those of their affiliated organizations, or those of the publisher, the editors, and the reviewers. Any product that may be evaluated in this article, or claim that may be made by its manufacturer, is not guaranteed or endorsed by the publisher.

Copyright (c) 2022 López Mendoza and Alcántara Quintana. This is an open-access article distributed under the terms of the Creative Commons Attribution License (CC $B Y)$. The use, distribution or reproduction in other forums is permitted, provided the original author(s) and the copyright owner(s) are credited and that the original publication in this journal is cited, in accordance with accepted academic practice. No use, distribution or reproduction is permitted which does not comply with these terms. 